\title{
DIPLOMACIA EUROPEIA: DESÍGNIOS E MEIOS DA INTEGRAÇÃO EUROPEIA DE PORTUGAL (1945-1986)
}

\author{
EUROPEAN DIPLOMACY: PURPOSES AND MEANS OF \\ PORTUGAL'S EUROPEAN INTEGRATION (1945-1986)
}

Maria Fernanda Rollo*

Resumo: No final da II Guerra Mundial, Portugal, como de resto a generalidade dos países da Europa Ocidental, encetou o seu envolvimento no genericamente designado processo de construção da Europa, então claramente impulsionado no âmbito do Plano Marshall.

A II Guerra Mundial, no decurso da qual o Governo português manteve uma posição de neutralidade, trouxe-lhe contudo algumas dificuldades. Os efeitos da guerra geraram descontentamentos vários na sociedade portuguesa, mas também lhe ofereceram novas oportunidades. Inicialmente, a ambiguidade da neutralidade que Portugal desenvolvera colocara-o numa posição algo fragilizada no concerto internacional, mas um segundo momento, de neutralidade colaborante com os aliados, acabou por jogar a seu favor. De resto, o apoio aliado foi fundamental para a sobrevivência do regime; ao mesmo tempo que a vitória das democracias ocidentais dava novo fôlego às oposições que, fortalecidas, se movimentariam contra o regime. Mas este recompôs-se, reforçou-se e contra-atacou. Todavia, a situação internacional alterara-se irreversivelmente, abrindo as portas a posicionamentos e transformações que se viriam a revelar duradouros.

Nesse contexto, o ressurgimento, sob novos moldes, das possibilidades da cooperação europeia tal como foi sendo concebida e veio a ser construída a partir dos finais da II Guerra Mundial colocou Portugal perante a necessidade de repensar a sua posição em matéria de política externa, pelo menos informalmente, empurrando-o inexoravelmente para o palco europeu.

$\mathrm{Na}$ prática, o regime ver-se-ia obrigado a uma aproximação à Europa e aos EUA, sobretudo no contexto da participação de Portugal no Plano Marshall. Embora forçado e a contragosto, este momento acabaria por revelar-se o início de um processo de internacionalização e de envolvimento nos movimentos de cooperação europeia.

Até ao final do Estado Novo a opção manteve-se indesejada, obrigando a um 
esforço constante para resolver as contradições existentes entre a realidade e as convicções e os princípios políticos pelos quais se batia e que em vão desejava fazer perdurar; os comportamentos das autoridades portuguesas, embora aparentemente incoerentes e naturalmente encerrando alguma diversidade de opiniões e posições, caracterizaram-se por atitudes ambíguas, assumindo globalmente uma cooperação económica internacional condicional e condicionada, pragmática e versátil: reajustável às circunstâncias ocorrentes, capaz de promover mudanças pragmáticas de rumo, procurando, no fundo, conciliar uma opção europeia ou atlântica, da qual jamais quis ficar 'de fora' e uma opção 'africanista', de unidade com as colónias, da qual não queria nem porventura podia abrir mão.

Em breve, o andar dos tempos acabaria por conduzir Portugal à resignação face à constituição de uma unidade de estrutura económica da Europa.

Foi já nos anos finais do Regime, durante o consulado marcelista, que a candidatura britânica de adesão às Comunidades Europeias arrastou a decisão portuguesa.

$\mathrm{Na}$ realidade, Portugal, prosseguindo os passos da Grã-Bretanha e compreendendo novamente que não podia ficar à margem do 'processo Europa', partiu para as negociações que o haveriam de conduzir à assinatura do Acordo de Comércio Livre Portugal - CEE e do Acordo Portugal - CECA (este último sobre o comércio dos produtos siderúrgicos) em 22 de Julho de 1972.

Porém, o pedido de adesão às Comunidades só se cumpriu depois da Revolução de 25 de Abril de 1974 que depôs o regime do Estado Novo e instaurou a Democracia.

Palavras-chave: Portugal, Estado Novo, Europa, Construção Europeia, Diplomacia

Abstract: At the end of World War II, Portugal became involved in the designated process of building Europe, driven by the Marshall Plan.

World War II, in which the Portuguese Government maintained a position of neutrality, brought it difficulties. Initially it placed Portugal in a weakened position, but subsequently, the neutrality cooperating with allies turned out to play in its favor. Moreover, allied support was crucial to the regime's survival and in breathing new life into the opposition, which, strengthened, would move against it. In this context, the resurgence of possibilities of European cooperation within a new situation gave Portugal the need to rethink its position on foreign policy, pushing it inexorably onto the European stage. In practice, the regime would be obligated to get closer to Europe and the USA. By the end of the Estado Novo Period (The New State Period) the option remained unwanted, requiring a constant effort to reconcile the contradictions between reality, beliefs, and the political principles for which it fought. It was 
in the final years of the regime, during The Marcelista Consulate, that the British application to join European Communities drew out the Portuguese decision. In fact, Portugal, following in the footsteps of United Kingdom, realized they could not sit on the sidelines of 'Europe process', and started off negotiations that would lead to the signing of Portugal Free Trade Agreement - CEE, and the Portugal Agreement - CECA, on July 22, 1972.

However, the application for acceptance into the Communities was only to be fulfilled after the Revolution of April 25, 1974 which overthrew the Estado Novo regime and established democracy.

Keywords: Portugal, Estado Novo (New State), Europe, European Construction, Diplomacy

\section{INTRODUÇÃO}

Este artigo estuda o processo da integração europeia de Portugal que teve início no pós-Segunda Guerra Mundial até se concretizar formalmente através da assinatura do Tratado de Adesão às Comunidades Europeias celebrado em Junho de 1985.

A história do envolvimento e da participação de Portugal no processo de construção da unidade europeia é observado confrontando o contexto histórico e as opções políticas que o condicionaram e o enquadramento institucional que o concretizou, procurando caracterizar a formação, comportamento e contornos da diplomacia europeia portuguesa.

Embora a resistência e a adversidade do Estado Novo ${ }^{1}$ relativamente ao movimento de cooperação europeia, o envolvimento e a participação de Portugal acabaram por ocorrer e condicionar favoravelmente o percurso interno e enquadramento internacional do país, proporcionando-lhe evidentes vantagens e benefícios durante um período considerável e decisivo, especialmente no contexto da participação na OECE a partir de 1948 e da EFTA a partir de 1960. A prazo, todavia, as oportunidades e os impactos positivos esgotar-se-iam, a partir da alteração provocada pela saída da GrãBretanha da EFTA e adesão à CEE e dos limites colocados pela natureza do Estado Novo que, de resto, interditavam a sua integração no Mercado Comum. Essa, teria que esperar pela Revolução de Abril de 1974 e pelo contexto democrático daí emergente que, de resto, ajudou a consolidar. Assim, considerando a natureza do regime político ditatorial que então vigorava em Portugal, as linhas explicitamente avessas que orientavam a sua política externa em termos de cooperação internacional e os propósitos de autarcia económica prosseguidos, a posição de neutralidade do País durante a Segunda Guerra Mundial e as favoráveis condições económicas em que se encontrava no final do conflito, a sua dimensão colonialista e a sua posição relativamente periférica no quadro europeu, procurar-se-á identificar os argumentos e os condicionalismos que proporcionaram e conduziram ao envolvimento no 
movimento de cooperação/integração europeia.

\section{NO FINAL DA GUERRA: A COOPERAÇÃO COMO INEXORABILIDADE}

O final da II Guerra Mundial determinou a afirmação e a concretização, em diversos e novos moldes, dos movimentos de cooperação e, genericamente, do processo unificação europeia.

Qualquer que fosse a perspectiva, o Mundo mudara, e eram complexos os pressupostos da sua reorganização. Situação que, em parte, e desde logo, decorria da grande evidência que o conflito fizera ressaltar: "A Europa já não era um centro de poder mundial; doravante, o equilíbrio repousava nos EUA, não europeus, e na URSS, semi-europeia"?

O encontro dos soldados americanos e russos em Abril de 1945 no Elba fora já um sinal evidente, representando simbolicamente o 'apagamento' da Europa e as forças determinantes da ordem mundial. Os dados da paz, apesar de terem sido lançados pelos três Grandes, incluindo naturalmente o Reino Unido, não deixavam de tornar patente esse apagamento. Quem, no imediato pós-guerra, ditava as linhas fundamentais eram os dois grandes vencedores: Roosevelt e Staline. A Grã-Bretanha que representava os vencedores da Europa não tinha um projeto europeu e Churchill manter-se-ia quase sempre "colado" às posições americanas.

Desde muito cedo que se sabia que o final da Guerra, independentemente do seu desenlace, traria uma realidade internacional profundamente diferente da existente antes da deflagração do conflito e à medida que se foi clarificando o desfecho da Guerra intensificaram-se as preocupações e as tentativas de preparar a organização da futura ordem internacional, nomeadamente em matéria de relações económicas internacionais - como o testemunham os acordos de Bretton Woods.

Face às novas realidades, a necessidade da cooperação impor-se-ia com mais força que outrora, quer para os dirigentes, quer para as opiniões públicas desamparadas a quem o nacionalismo enfraquecido já não servia de suporte para os combates pela paz e pela reconstrução que era necessário travar. A prazo, acumular-se-iam três fortes razões para as nações europeias encararem seriamente a necessidade de cooperar entre si:

- a primeira, decorrente da escassez e dos próprios limites com que a Europa se veria confrontada. Exaurida, tentou pelos seus meios uma primeira reconstrução, mas as respostas individuais acabaram por fracassar uma a uma e os diversos países acabariam por cair numa crise que lhes era comum. A solução mostrou-se insuficiente e ineficaz para resolver os problemas complexos com que a Europa se debatia, ao mesmo tempo que compreendia que já não era um centro de decisão mundial;

- a segunda era constituída pelos presumíveis intuitos expansionistas 
soviéticos, ameaçando pôr em risco o que ainda sobrava do sistema capitalista liberal. O avanço soviético foi, efetivamente, introduzido como um elemento novo a ser ponderado no sentido da procura de uma consciência comunitária europeia - o leit-motiv para a cooperação dos europeus: o problema já não residia na ameaça alemã mas sim no perigo 'vermelho' que obrigava cada país a defender-se internamente do comunismo e, externamente, da pressão soviética. A Europa que procurava a união passava agora a excluir o mundo soviético;

- por fim, a terceira, decorrendo das pressões exercidas pelos EUA, que, a partir de 1947-48, apenas garantiam a ajuda necessária a troco da consolidação da cooperação europeia. Na realidade, só quando os EUA mostraram que faziam depender o seu auxílio de uma acção europeia concertada é que os governos europeus, porventura tardiamente, se decidiram a tomar iniciativas no sentido da cooperação que o início da Guerra Fria de certa forma congelara.

Quanto a Portugal, a influência do contexto e do cenário internacionais durante a guerra e no pós-guerra, tiveram um impacto e uma influência muito superiores ao que as autoridades políticas desejavam e presumiam, sobretudo considerando as ideias e as posições de autarcia e independência que o Estado Novo prosseguia. Em quase todas as circunstâncias as idiossincrasias políticas e as debilidades económicas nacionais acabariam por expor vulnerabilidades e impor soluções de compromisso e cooperação.

Inicialmente, a ambiguidade da neutralidade que Portugal desenvolvera colocara o País numa posição algo fragilizada no concerto internacional, mas, um segundo momento, de neutralidade colaborante com os Aliados, acabaria por jogar a seu favor. De resto, o apoio aliado foi fundamental para a sobrevivência do regime político português; sobretudo porque, ao mesmo tempo, a vitória das democracias ocidentais dava novo fôlego às oposições que, sentindo-se fortalecidas, se movimentavam contra o Estado Novo.

Aos perturbadores tempos de conflagração militar sucederiam os não menos complexos tempos de paz. Politicamente, o poder instituído abriu brechas e viu-se defrontado como uma viva e séria contestação, que deixou marcas para os anos vindouros. Sem dúvida, a II Guerra Mundial provocou alguns dissabores e sérias dificuldades às autoridades portuguesas. Mas, vulnerabilidades protegidas e dificuldades 'vencidas', o Estado Novo sobreviveu; e, uma vez passada a crise, surgiria revigorado e recomposto.

Na realidade, a II Guerra Mundial constituíra um inequívoco momento de viragem, tendo determinado a manifestação de uma primeira crise política do Estado Novo, e, alterando o registo em que se ia processando a atividade económica nacional, provocado uma interrupção do percurso e do cenário de estabilidade monetária e financeira e imposto uma reorientação no rumo e no ritmo que orientavam a condução económica do País ${ }^{3}$. 
Embora a posição de neutralidade foram profundos os efeitos económicos propagados pela situação de beligerância, obrigando à adopção de uma verdadeira economia de guerra. Situação que, demonstrando a forte dependência da economia nacional relativamente ao comércio externo (sobretudo em matéria de abastecimentos), denunciava a importância de um conjunto de vulnerabilidades estruturais que enformavam a realidade económica portuguesa no que respeitava à natureza e composição do seu tecido produtivo. Essa situação suscitou uma reflexão sobre a textura da economia portuguesa que proporcionou a tomada de consciência dos limites impostos pelo seu fraco desempenho em termos de produção, revelando em especial as debilidades da sua malha industrial, abrindo caminho à aceitação, e aprovação, de um programa de modernização económica consubstanciado principalmente na adopção e implementação de um plano de electrificação e na aceitação de um programa de industrialização ${ }^{4}$, que ficaria em boa medida comprometido por obstáculos de natureza diversa.

À amarga denúncia da dependência externa, evidenciada no contexto de escassez generalizada, acentuadas restrições e dificuldades de abastecimento impostas pelo conflito, associou-se um complexo cortejo de efeitos internos em matéria de inflação, mercado negro, contrabando, acompanhando alterações introduzidas no sistema produtivo como reação a mercados a funcionar em condições excepcionais num quadro de disfunções crescentes.

Tornou-se rapidamente evidente, pelo menos para alguns observadores, que a Guerra, afinal, constituía um duro teste à capacidade económica portuguesa, sobretudo enquanto encarada num quadro de autarcia económica. O mais interessante é que a solução que se pretendeu encontrar assumiu um carácter acentuadamente nacionalista e se encaminhou precisamente no sentido de reforçar esse postulado de independência económica.

A situação existente e o tipo de soluções que se procuraram impor à economia portuguesa não impediram que o período da Guerra tivesse constituído um espaço de prosperidade relativa e um período de enriquecimento de muitos agentes económicos, incluindo o Estado.

Durante os anos da Guerra, Portugal registou uma acumulação excepcional de ouro e de divisas no Banco de Portugal, de consideráveis disponibilidades na conta do Tesouro e de aumentos substanciais nos depósitos bancários, que a par com um fraco nível de investimento interno, permitiu que, terminado o conflito, o País gozasse de uma situação financeira confortável contrastando fortemente com o estado em que se encontravam a maior parte dos países europeus envolvidos no conflito. Situação que se fez reflectir num extraordinário desenvolvimento da circulação fiduciária e que resultava da combinação de vários factores, em particular, a entrada de capitais (novos, retornados ou transportados pelos refugiados), o afluxo de divisas, propiciando uma importante acumulação de reservas cambais (em especial 
por conta das compras e investimentos dos beligerantes) e o aumento dos rendimentos invisíveis. Além disso, Portugal tinha um crédito sobre Inglaterra avaliado, no final da Guerra, em cerca 80 milhões de libras. Em resumo, uma situação financeira desafogada quer a nível das contas do Estado, quer a nível das entidades privadas, não obstante os sintomas inflacionistas daí resultantes se apresentarem desde logo como uma das preocupações principais da política económica e financeira do governo.

A esses factores somavam-se no sistema bancário os saldos positivos dos negócios de guerra, os rendimentos do contrabando e os réditos dos circuitos 'ilegais' como o mercado negro. Em geral, a evolução foi no sentido do aumento regular do total dos meios de pagamento ao longo do período, sendo assinalável a proporção retida pelo sistema bancário, apadrinhada pelo Governo no sentido de contribuir para a sua luta contra a inflação crescente. Riquezas somadas, nas mãos do Estado, no sistema bancário e entre poupanças privadas, que constituíam um significativo espólio de Guerra; aconteceu porém que a sua aplicação se manteve modesta e condicionada em termos de investimentos produtivos e que, tendo embora permitido perspectivar com tranquilidade os anos seguintes em matéria de recursos financeiros do Estado, acabaram por se revelar insuficientes, esgotando-se num curto espaço de tempo. De qualquer forma, as intenções e os objectivos enunciados pelos responsáveis pela política monetária portuguesa tinham sido alcançados quanto ao essencial, sobretudo no respeitante ao valor do escudo e as suas garantias.

A literatura tem sublinhado essa imagem de prosperidade momentaneamente encontrada com a Guerra. Da mesma forma que tem assinalado a importância de alguns dos seus efeitos positivos sem deixar de apontar que em certa medida as oportunidades propiciadas pela Guerra não terão sido plenamente exploradas em termos futuros. Para mais, tem sido constatado, a partir dos indicadores económicos disponíveis, que o período correspondente à II Guerra, constituiu uma fase pouco significativa em termos de crescimento. Imagens aferidas, a verdade é que o País enriqueceu muito mas cresceu pouco 5 .

Por circunstâncias e razões que tiveram a ver com a combinação da conjuntura bélica e a textura da economia portuguesa, verifica-se que a produção nacional cresceu muito pouco durante os anos de guerra e que o PIB per capita em 1946 não era muito superior ao $1939^{6}$, contrastando, como apontou Silva Lopes, com o que ocorreu em países que, tal como Portugal, mantiveram uma posição de neutralidade durante a Guerra.

Em breve constatou-se que as expectativas positivas que a Guerra gerou não se desenvolveram nem concretizaram plenamente, denunciando o carácter temporário da prosperidade, e a natureza da mesma, a que continuava a faltar um processo de modernização nos sectores de atividade. Na verdade, 
a prosperidade sentida no fim da Guerra seria mais aparente que real, basicamente porque a Guerra gerou riqueza e não fontes permanentes e auto sustentadas de produção de rendimentos.

Tornou-se evidente que o esforço conjuntural, desenvolvido no sentido de aproveitar as vantagens adquiridas, integrar novos 'rumos' que permitissem suprir as vulnerabilidades do tecido produtivo nacional e contrariar os reflexos negativos que se foram fazendo sentir durante e depois do conflito mundial, não poderia ter efeitos imediatos, sendo difícil contrariar tendências há muito instaladas. Situação a que acrescia o quadro de reservas e condicionalismos impostos pelas autoridades portuguesas, nomeadamente no que se referia à manutenção dos equilíbrios políticos e sociais internos, ao espartilho da organização corporativa e ao rigoroso cumprimento dos princípios dogmáticos da política financeira tradicional, que enquadravam, definiam limites e, na prática, se sobrepunham à prossecução dessa estratégia.

A segurança que as substanciais reservas em ouro e divisas ofereciam ver-se-ia rapidamente confrontada com a diminuição das exportações que a guerra favorecera e as necessidades impostas pela execução do programa de modernização em curso. O regresso à 'normalidade', tão caro às autoridades portuguesas, tornou ainda mais evidente a vulnerabilidade da situação económica nacional, sobretudo do seu aparelho produtivo, colocando de novo as dificuldades de exportação dos produtos tradicionalmente produzidos em Portugal e afirmando a dependência do País das importações do exterior, sobretudo dos seus tradicionais parceiros europeus, tendo reflexos acentuadamente negativos nas balança comercial e de pagamentos, gerando uma crise que resistia às terapêuticas e controles habituais.

Sucedeu assim que ao longo dos primeiros meses de 1948 se assistiu, pela primeira vez desde a institucionalização do Estado Novo, a uma deterioração acentuada da situação financeira e cambial portuguesa. A conjuntura económica e financeira do País vinha, aliás, revelando sintomas de precariedade desde 1947 e, já nessa altura, tudo indicava que a situação se viesse a agravar, como aliás aconteceu. Como resultado de tudo isto, registouse uma acentuada diminuição das reservas em ouro e divisas, mais visível nos anos de 1947 a 1949, ameaçando o equilíbrio financeiro que constituía uma das 'pedras de toque' da política económica do Estado Novo.

Afinal, Portugal, embora mais tardiamente e com contornos ligeiramente diferentes, comungava de uma crise internacional que afligia a generalidade dos países europeus e que estivera na origem do discurso que o general Marshall proferira em Junho de 1947 e na consequente elaboração do Plano Marshall.

Portugal participou ativa e plenamente nas diversas ações destinadas à concretização do Plano Marshall': esteve presente na Conferência de Cooperação Económica Europeia, realizada em Julho de 1947 em Paris, onde 
em resposta às sugestões do general Marshall se fez o balanço das necessidades económicas comuns e se elaborou um programa de recuperação económica dos países europeus; aceitou os vários mecanismos instituídos no quadro do European Recovery Program ('nome oficial' do Plano Marshall); foi membro fundador da Organização Europeia de Cooperação Económica (OECE, mais tarde OCDE) e beneficiou do auxílio financeiro norte-americano, apesar de inicialmente o ter rejeitado.

Num primeiro momento, o Governo português, pela voz do seu ministro dos Negócios Estrangeiros, Caeiro da Mata, rejeitou a possibilidade de aceitar auxílio financeiro americano. Era a fase em que os princípios, as convicções políticas e ideológicas, postos em confronto com as novas realidades, se sobrepunham claramente a estas últimas. No plano da política externa, a decisão da rejeição correspondia a uma forma de compromisso entre a vontade de preservar os grandes princípios pelos quais se regia a diplomacia de Oliveira Salazar e estar presente em Paris. Efetivamente, o Governo português queria manter o País economicamente autónomo, mas dependia, em assinalável proporção, dos fornecimentos do exterior para 'viver' e para se autonomizar. Por isso, embora a abominação das consequências económicas da cooperação fosse real, a aproximação aos seus principais parceiros comerciais impunha-se-lhe de forma inexorável. Evidentemente, a dependência externa impunha estreitos limites à autarcia desejada.

Contudo, decorreu apenas um ano para que o Governo português, confrontado com o agravamento da situação económica e financeira do País, se visse obrigado, contrariando os princípios que inspiravam a sua conduta externa, a alterar a decisão inicial de dispensar o auxílio financeiro dos EUA no quadro do Plano Marshall, envolvendo-se, embora de forma defensiva, no processo de cooperação económica que entretanto tenderia a consolidar-se no quadro da Europa Ocidental e abrindo espaço à crescente internacionalização da economia portuguesa. Foi em vão que, no quadro de algum optimismo e de um acentuado voluntarismo, se procurou contrariar essa tendência de deterioração acentuada da situação financeira e cambial nacional. Sobretudo porque a atitude de sobreavaliação das capacidades e potencialidades do aparelho económico nacional e dos resultados do programa industrial, desenvolvida no quadro de um arreigado espírito de autarcia económica, era acompanhada por uma atitude de subestimação da dimensão e dos efeitos que a crise internacional de comércio e pagamentos de 1947 teria em Portugal. Tendo evitado, até ao limite da sua capacidade negocial, recorrer ao financiamento norte-americano, a 20 de Julho de 1948, Oliveira Salazar, colocou, por fim, a hipótese de recorrer ao auxílio Marshall. A impotência das autoridades portuguesas face à implacabilidade da crise financeira e comercial que alastrava no País não ofereciam mais alternativas. Perante o dilema: o auxílio americano ou a ruptura monetária e financeira, 
o Presidente do Conselho usou da flexibilidade necessária para conduzir uma das mais significativas alterações da política externa portuguesa levada a cabo durante a vigência do Estado Novo. Às razões de ordem política e ideológica, e não obstante o cepticismo em relação às soluções de cooperação económica internacionalmente encontradas, sobrepuseram-se e prevaleceram afinal factores pragmáticos de ordem económica e financeira.

Em consequência, o Governo português empenhou-se para que Portugal fosse contemplado na distribuição dos créditos americanos e, diretamente ou através dos seus representantes diplomáticos, devendo neste contexto sublinhar-se a importância da ação do embaixador Rui Teixeira Guerra $^{8}$ (como de resto em toda a história que conduziu ao envolvimento de Portugal nos movimentos de cooperação europeia desde o pós Guerra até à adesão às Comunidades), envidou todos os esforços junto do Governo norteamericano, da administração americana do Plano Marshall e da OECE, no sentido de obter o máximo auxílio financeiro norte-americano.

O envolvimento de Portugal no Plano Marshall teve uma importância relevante na estruturação de um processo controlado do desenvolvimento económico 9 . Na prática, o Plano Marshall constituiu a razão e a oportunidade para a formulação de um programa económico para o pós-guerra, condensando o essencial das perspectivas do Governo em matéria de política económica e orientando a sua atuação até à entrada em execução do I Plano de Fomento (1953-1958). Neste contexto é aliás de apontar como o envolvimento de Portugal no Plano Marshall contribuiu para a adesão a novas formas de encarar a política económica através do planeamento económico materializado nos sucessivos planos de fomento que passaram a orientar a atividade económica portuguesa até ao fim do Estado Novo.

No seu conjunto, a participação de Portugal no Plano Marshall propiciou-lhe uma assistência financeira que rondou os 90 milhões de dólares (mais de dois milhões e meio de contos), interessando uma parte significativa dos agentes económicos do País, incluindo o próprio Estado. A verba não é significativa, especialmente se comparada com os outros países beneficiários. Todavia, foi conjunturalmente importante no que respeita à contenção e superação da crise multifacetada que na altura afectava a economia e a sociedade portuguesas; através dos mecanismos que desencadeou, o auxílio do ERP contribuiu para eliminar o défice da balança de pagamentos e facilitou o abastecimento de bens essenciais necessários para debelar a crise e para the minorar os efeitos económicos e sociais; da mesma forma, viabilizou a aquisição de equipamentos para alguns projetos que dependiam desse fornecimento para o início ou a prossecução da sua atividade, participando no investimento em atividades económicas em parte integradas no recém aprovado programa de industrialização e para o prosseguimento da construção de algumas infra estruturas, designadamente barragens produtoras de energia eléctrica. Deve 
também salientar-se a importância dos estudos dos técnicos estrangeiros, sobretudo americanos, sobre aspectos precisos da economia portuguesa. De resto, a participação de Portugal nos diversos programas desenvolvidos no quadro do Plano Marshall proporcionou o desenvolvimento de um caldo de cultura que alargou a sua influência a uma parte da sociedade portuguesa, permitiu intensificar contactos e conhecer novas realidades internacionais, deu lugar à afirmação de um corpo de diplomatas especificamente dedicado às relações europeias e, em estreita articulação, à constituição de uma elite técnica formada nos contactos e nos trabalhos levados a efeito no interior da multiplicidade de instituições internacionais (na primeira linha das quais se encontra naturalmente a OECE) e ao acréscimo de conhecimento sobre os meandros do comércio internacional e à aprendizagem intensiva para lidar com os novos instrumentos do sistema monetário e financeiro internacional nascido em Bretton Woods. Será de destacar a importância e o impacto profundo e duradouro das alterações introduzidas na administração pública portuguesa obedecendo e reagindo aos imperativos da aplicação do Plano Marshall a Portugal. Destaque-se entre tudo, a criação da CTCEE - Comissão Técnica de Cooperação Económica Europeia (mais tarde Externa) ${ }^{10}$ confiando-lhe as missões de realizar ou promover os estudos respeitantes à comparticipação de Portugal na Organização Europeia de Cooperação Económica; elaborar, reunir e prestar às entidades encarregadas da representação portuguesa na referida Organização os elementos e informações que por esta sejam solicitados e assegurar a comparticipação técnica portuguesa nos trabalhos da mesma Organização. Foi no seio ou em articulação com a CTCEE, beneficiando de um enquadramento institucional e condições de funcionamento excepcionais, que em boa medida se formou, sedimentou e afirmou a referida elite técnica e diplomata acima referida. Inicialmente dependente diretamente do Conselho de Ministros para o Comércio Externo, em breve viu as suas funções alargadas, ganhando maior desenvolvimento e meios de ação e assumindo uma nova estrutura, passando a funcionar junto do Ministério das Finanças. Em 1951 transitou para a dependência direta da Presidência do Conselho e a sua designação passou a Comissão Técnica de Cooperação Económica Externa, em consequência de se iniciar a sua intervenção nos trabalhos destinados à NATO. Posteriormente, a CTCEE foi sofrendo evoluções de ajustamento à conjuntura nacional em boa parte refletindo a forma como se foram definindo os contornos e instituindo os moldes em que se desenvolveram as várias instituições de cooperação económica internacional. Na prática, esta instituição passou a assegurar boa parte das relações económicas externas de Portugal, no que diz respeito aos elementos necessários e mesmo à representação do País. Por ela passaram, de alguma forma e de forma mais ou menos intensa, as negociações e as relações de Portugal com a OECE/OCDE, União Europeia de Pagamentos - UEP, a Mutual Security Agency - MSA, a NATO, a FOA, o 
GATT ou a CEE - evocando apenas as instituições mais visíveis.

Para além da formação da equipa portuguesa deve acrescentar-se como o contexto do aproveitamento do Plano Marshall em Portugal abriu inusitadamente o País à presença de especialistas estrangeiros, contribuindo para um processo de crescente abertura do Estado Novo que dificilmente podia regredir. Também por isso, a participação de Portugal no Plano Marshall contribuiu para a intensificação do seu envolvimento num processo de crescente europeização e internacionalização e abertura ao exterior. Portugal dava assim os primeiros passos da sua 'aventura europeia'.

A história da participação de Portugal no Plano Marshall foi parte integrante de uma conjuntura de passagem. Foi ponte de saída do fim da II Guerra Mundial, entre a cooperação e auto suficiência, entre o Portugal acentuadamente agrícola e o Portugal industrial que se sobrepôs à projeção do País rural. $\mathrm{O}$ facto de se ver integrado nas novas instituições internacionais a que o Plano Marshall deu origem (além da OECE a UEP), trouxe-lhe vantagens de diversa ordem e grandeza, passando pela formação da referida elite diplomática e técnica. Portugal garantiu dessa forma, a contragosto, conjugando resistências e vantagens habilmente geridas e sempre de forma reticente e condicionada, a sua integração no sistema de comércio e de pagamentos internacional e, sobretudo, a sua presença ativa nos movimentos nascentes de cooperação económica europeia num processo que desembocaria num primeiro momento na integração na EFTA e, quarenta anos mais tarde, na sua adesão à CEE em 1986.

De sublinhar, porém, que essa aproximação à Europa, em particular ao longo da década de 50, se operou no quadro de uma quase inevitabilidade, sobretudo por pressão das circunstâncias realidade internacional. Tratouse sobretudo de uma inexorabilidade e de uma reação ao peso do 'cerco internacional', que se procurou combinar com a viragem para as colónias. No fundo, tentou-se preservar o essencial da realidade existente, pretendendo, tanto quanto possível, conciliar duas trajetórias tendencialmente divergentes: a autarcia que o Regime almejava e a internacionalização que a realidade externa impunha.

É certo que a situação internacional se alterara irreversivelmente, e, nesse contexto, o ressurgimento, sob novos moldes, das possibilidades da cooperação europeia tal como foi sendo concebida e veio a ser construída a partir dos finais da II Guerra Mundial, colocaria Portugal perante a necessidade de repensar a sua posição em matéria de política externa, pelo menos informalmente, empurrando-o inexoravelmente para o palco europeu. Assumindo globalmente a cooperação económica internacional, de forma pragmática e versátil, o País foi-se reajustando às circunstâncias ocorrentes, promovendo mudanças de rumo, procurando, no fundo, conciliar uma opção europeia ou atlântica, das quais jamais quis ficar 'de fora' com uma opção 
'africanista', de unidade com as colónias, de que não queria nem, porventura, podia abrir mão.

De resto, as grandes linhas de orientação da política externa portuguesa estavam claramente traçadas ${ }^{11}$. A estratégia que se advogava em Portugal para o pós-Guerra consistia essencialmente na defesa da manutenção da política externa portuguesa tradicional, assente nos seus quatro vectores preferenciais: o Brasil, a Espanha, a Inglaterra e as colónias africanas. Quanto às colónias, começam-se a definir no início da década de 50, embora ainda de forma incipiente, os princípios de um futuro projeto dando expressão à ideia da criação de uma unidade portuguesa que integrasse o Continente e as colónias, que efetivamente se constituiria mais tarde sob a designação de Espaço Económico Português ou Mercado Único Português.

A acrescentar nestes tempos do pós-Guerra: um sentimento visceral de anticomunismo e uma acentuada desconfiança em relação aos EUA que envolvia o pensamento político dos principais responsáveis do regime. No contexto da 'guerra fria' estas duas posições opostas tendiam a alastrar as suas contradições para o território europeu e, se a primeira aversão não tinha efeitos de monta na conduta da política externa portuguesa ela podia obrigar a uma aproximação, empurrar para uma adesão progressiva ao lado oposto motivada pela necessidade de defender o mundo ocidental da URSS. De facto, a evolução dos acontecimentos viria a impor um crescente estreitamento nas relações de Portugal com os EUA.

Além de todos os acontecimentos em torno do Plano Marshall, a assinatura em Fevereiro de 1948 de um acordo entre o Governo português e o governo dos EUA, concedendo às forças militares americanas facilidades nos Açores e, numa esfera mais abrangente, a admissão de Portugal como membro fundador da NATO em 4 de Abril de 1949. Condições criadas ou aceites que propiciaram que Portugal tivesse vivido nos anos 50, em plena Guerra Fria, um período de franca aceitação por parte dos países ocidentais e não só.

Entretanto, os ventos da descolonização que vinham já percorrendo os impérios europeus aproximavam-se e, muito em breve viriam colocar sérias dificuldades a Portugal.

\section{ENTRE OS EUROPEUS DA EFTA: A COOPERAÇÃO NECESSÁRIA}

A seguir ao período mais conturbado do pós-guerra e, em particular, aos acontecimentos em torno das eleições presidenciais de 1949, o Estado Novo logrou impor um clima de pacificação interna e de anulação das oposições que perdurou praticamente até ao final da década de 50 quando, em 1957, foi lançada a «candidatura independente» do general Humberto Delgado às eleições presidenciais de 1958. Reacenderam-se as tensões em torno daquele que veio a constituir o maior movimento de contestação ao 
regime de Oliveira Salazar; o País, de Norte a Sul, viveu ansiosamente os acontecimentos. Reclamando contra uma maciça fraude eleitoral, Delgado foi vencido nas urnas... Américo Tomás foi eleito Presidente da República. Mas o País mudara. A agitação política, proveniente de diversos quadrantes, os protestos populares, a contestação em geral prosseguiu recheada de acontecimentos na transição da década. E não era só a política interna que estava diferente.

Resolvidas algumas hesitações e ultrapassados diversos impasses, superada a crise dos abastecimentos e de pagamentos externos que irrompeu com estrépito no final dos anos 40, apesar de todos os atrasos, Portugal do pósGuerra acabaria por conhecer um processo de desenvolvimento económico e social que acompanhou e até ultrapassou, em termos das principais taxas de crescimento, o clima de prosperidade que caracterizou a economia do conjunto dos países europeus nas duas décadas seguintes.

Cumpriu-se o difícil processo de transição da conjuntura da economia de Guerra, com tudo o que envolveu, até em termos de indicação de estratégias e projetos para o País, para o tempo de paz e de guerra fria. A partir daí, desenhou-se um ciclo de crescimento e de modernização que incorporou mudanças estruturais, não obstante a existência de poderosos factores sociais e políticos de resistência que, subsistindo, haviam de condicionar negativamente o ritmo e o alcance das transformações modernizadoras. Entre as principais alterações, refira-se a plataforma de cooperação económica europeia / externa encontrada e os efeitos que teve nomeadamente em termos de liberalização e estímulo ao desenvolvimento das trocas, em que Portugal também esteve envolvido e do qual, conforme referido, beneficiou em primeira instância através da sua participação no Plano Marshall, na OECE e na UEP.

A nova estratégia político-económica do Estado Novo encetada na década de 50, procurando enquadrar coerentemente os grandes objectivos da política económica nos então chamados "planos de fomento", constituiu um elemento essencial na significativa evolução da economia portuguesa, promovendo, em obediência às tendências gerais do capitalismo europeu, as condições que viriam proporcionar um acentuado crescimento do sector industrial.

Globalmente, porém, a estratégia dos anos 50, que confiava o crescimento económico à expansão industrial (assente, no fundo, em dois estímulos: a reserva de mercados e o baixo preço dos factores produtivos mão-de-obra e capital) e a própria estrutura do modelo criado para sustentar esse mesmo 'arranque', vieram a revelar-se insuficientes e incapazes acabando por se repercutir negativamente no próprio desenvolvimento do País - o que permite concluir que a concepção do projeto assentava em pressupostos cuja viabilidade era duvidosa e, duvidoso também, o próprio princípio desenvolvimentista em que a nova estratégia se baseava. De resto, mesmo 
melhorados, os ritmos de desenvolvimento mantiveram-se muito aquém dos índices do restante mundo ocidental industrializado.

Por outro lado, o final dos anos 50 e especialmente os inícios dos 60 vieram também colocar novos desafios a Portugal no que dizia respeito ao seu envolvimento nos movimentos de cooperação económica europeia, implicando importantes decisões e definindo estratégias consequentes.

Sobre todas estas questões refletiu-se ampla e profundamente naquele que foi o mais relevante acontecimento da segunda metade dos anos 50 e cujas repercussões se prolongaram por grande parte da década seguinte: os II congressos da Indústria Portuguesa e dos Economistas que reuniram em Lisboa a elite política e económica.

A sessão inaugural pertenceu ao ministro da Presidência, Marcelo Caetano. Discurso surpreendente, em que depois de fazer uma síntese da história da indústria portuguesa, identificando os seus problemas, apontando-lhe os defeitos e fraquezas, Caetano se referiu aos processos de integração europeia, colocando no centro de todas as preocupações a questão dos mercados e a necessidade de, esbatendo a tradicional tutela estatal, atribuir maior protagonismo aos agentes privados ${ }^{12}$.

As conclusões do Congresso sintetizam a maioria dos temas debatidos, incluindo a necessidade de não perder de vista as transformações derivadas dos movimentos de cooperação e integração europeia. ${ }^{13}$

A verdade é que a partir da realização desses Congressos os agentes económicos privados portugueses com interesses ligados à indústria e ao sistema financeiro impuseram em larga escala os seus pontos de vista, parte dos quais acabaram por ser vertidos para a forma final que foi dada ao II Plano de Fomento (1959-1964).

Todavia, para além dos planos e das instituições, as realidades económicas impuseram-se. Complexo e instante, o problema dos mercados, significando abertura, foi-se impondo e naquele passo hesitante de quem tem de satisfazer interesses nem sempre fáceis de conciliar, os governantes portugueses procuraram não perder completamente o que de mais importante se passava em termos da integração europeia.

Foquemos a nossa atenção nos três aspectos mais relevantes que a partir de então envolveram Portugal na história da construção europeia: a EFTA, o GATT e o primeiro pedido de negociações com a CEE.

É unanimemente aceite quer por aqueles que estiveram diretamente envolvidos nos acontecimentos quer por estudiosos que se têm dedicado a este assunto que foi "por um golpe de sorte", recorrendo à expressão do Embaixador Rui Teixeira Guerra, que "Portugal, apesar de estar longe de ter força económica comparável, conseguiu juntar-se aos outros propositores da "Pequena Zona" que vieram a negociar os acordos que, ultimados em Salsjobadem, culminaram na assinatura da Convenção de Estocolmo ${ }^{14}$. 
A forma como se conseguiu que Portugal viesse a integrar a EFTA, tendo suscitado alguma surpresa a nível internacional, ultrapassando o facto de não ter sido inicialmente convidado para participar nas negociações que conduziram a essa associação de comércio livre é conhecida, especialmente através do relato do que dela faz um dos protagonistas decisivos no desenrolar destes acontecimentos: o embaixador Calvet de Magalhães ${ }^{15}$. Perante a iminência da primeira reunião preparatória dos Seis se realizar sem a participação de uma delegação portuguesa alertou de imediato o então Secretário de Estado do Comércio: "O Dr. Correia de Oliveira concordou imediatamente comigo que teríamos que estar presentes nessa reunião pois corríamos o risco de vermos criados dois grupos económicos preferenciais na Europa e ficarmos de fora de ambos, com graves consequências para as nossas exportações e a nossa economia em geral" ${ }^{16}$.

Mais recentemente, José da Silva Lopes, que desempenhou um papel relevante nestas negociações, conta como a entrada de Portugal na EFTA foi essencialmente o resultado da ação (...) de José Gonçalo Correia de Oliveira, que, "a par da necessária ação diplomática no plano externo, em que foi eficazmente apoiado pelo embaixador R. Teixeira Guerra, teve, no plano interno, de procurar o apoio de Salazar e de lutar contra as forças do regime que mais defendiam o protecionismo". ${ }^{17}$

Não subsistem grandes dúvidas quanto à importância que Correia de Oliveira, o futuro ministro da Economia (secretário de Estado do Comércio entre 14.8.1958 e 4.5.1961, ministro de Estado adjunto do Presidente do Conselho entre 22.6.1961 e 19.3.1965 e, finalmente, ministro da Economia entre 19.3.1965 e 27.3.1968), assumiu na definição e condução da política económica e em particular nas suas relações externas durante este período.

De qualquer maneira, é inequívoca a forma como as autoridades portuguesas se bateram pela integração na Associação Europeia de Comércio Livre, argumentando contra a possibilidade de 'ficar de fora'.

A adesão à EFTA era particularmente apetecida porquanto a configuração que deveria assumir esta zona de comércio livre era consentânea com a política e com os princípios que orientavam a postura de Portugal relativamente à cooperação com o exterior.

Inserindo-se na EFTA, Portugal evitava ficar definitivamente arredado dos movimentos de integração europeia; os compromissos que assumia eram de natureza estritamente económica e comercial; não se levantavam (como na CEE) questões de regime ou de sistema político e muito menos problemas derivados da existência das colónias africanas, dada a completa autonomia aduaneira nas relações com terceiros países.

Além disso, o relativo subdesenvolvimento industrial português face às outras potências integrantes foi salvaguardado através da aceitação de um conjunto de exceções consagradas no Anexo G à Convenção de Estocolmo, 
através do qual se permitia a Portugal um muito mais lento desarmamento pautal (que se podia prolongar por 20 anos - o dobro do que era concedido aos outros membros) e, sobretudo, autorizava expressamente o País a erguer barreiras alfandegárias quando estivesse em causa a proteção de novas indústrias.

Mais uma vez Salazar cedia sem ceder. A realidade das coisas impunha-se-lhe. Limitava-se a dar-lhe continuidade evitando controvérsias desnecessárias e potencialmente perturbadoras. Em termos objectivos, a integração na EFTA constituía uma consequência natural do facto de ter estado presente desde a primeira hora na OECE.

$\mathrm{Na}$ realidade, a opção europeia de Portugal não só foi forçada como nunca se pôs verdadeiramente em termos de escolha entre a EFTA ou a CEE; a alternativa, se chegou a ser colocada, punha-se em termos de conservar ou perder o mercado europeu, não para além disso ${ }^{18}$.

Como pano de fundo da opção portuguesa, uma concepção economicista e utilitária da integração europeia. O facto do País comercialmente depender cada vez mais da Europa não suscitava (mais de dois terços do comércio externo fazia-se com países da zona europeia da $\mathrm{OECE}^{19}$ ), tão pouco, grandes reservas, tanto mais que o projeto ultramarino, mesmo na nova arquitetura que entretanto lhe seria dada pela institucionalização do Espaço Económico Português, derrapava em cada momento ficando permanentemente à beira de soçobrar à medida que os problemas políticos e económicos iam ganhando dimensões inesperadas.O próprio Salazar subscreveria parcialmente aquelas posições:

a técnica e a ambição de maior produtividade estão provocando a criação de grandes espaços económicos, à semelhança dos referidos acima, assentes sobre grandes bases nacionais. É assim que, independentemente das razões psicológicas e dos intentos políticos que estão na base da sua criação, se acaba de formar uma pequena Europa económica, ou o mercado comum das seis potências além-Pirinéus. Ainda que leve o seu tempo e apresente suas dificuldades a constituição integral e perfeita deste mercado, tal como o visionaram as potências fundadoras, a verdade é que a criação do mercado comum, ou, melhor, o seu começo de funcionamento rompe desde logo o equilíbrio das relações existentes com os outros países que dentro ou fora da Organização Europeia de Cooperação Económica (OECE) trabalham e comerceiam com cada uma dos que o constituem. A ideia de criar uma zona de comércio livre que abranja o mercado comum e a cadeia de países que de certo modo o envolve deve considerar-se como uma tentativa de salvaguardar os interesses destes 
países, sem destruir os progressos adquiridos quanto à liberdade de trocas e de liquidações internacionais em bases plurilaterais e monetárias estáveis. Longas, difíceis negociações se hão de seguir para encontrar o ponto de conciliação dos muitos interesses em jogo. Será possível? ${ }^{20}$.

Feito o balanço, a participação de Portugal na EFTA é avaliada, praticamente a todos os níveis, de forma muito satisfatória, considerando-a mesmo um dos mais poderosos factores do rápido crescimento e modernização da economia portuguesa durante esse período.

É conhecido que Portugal não só foi o País que manteve o mais elevado protecionismo aduaneiro no quadro dos países da EFTA (duas vezes e meia superiores à média dos outros parceiros) como foi também o país em relação ao qual o chamado "efeito-EFTA" teve maior impacto sobre o comércio: o aumento em percentagem do comércio externo português foi de $52 \%$ para as exportações e de $40 \%$ para as importações enquanto os restantes países constituintes da Associação não ultrapassaram os 30\% em qualquer dos fluxos.

O prosseguimento da integração significou o fim de um período onde predominaram as ideias de autarcia e, consequentemente, se iniciou uma maior abertura aos fluxos do comércio internacional e dos capitais estrangeiros, o aumento da competitividade de alguns dos mais importantes sectores produtivos e a aceleração do processo de concentração de capital que havia de conduzir à constituição de grandes grupos económico-financeiros.

A adesão à EFTA ficaria a constituir simbolicamente o primeiro elemento de expressão de um processo de abertura que, no fundo, significava a vitória da ideia e daqueles para quem a estratégia do desenvolvimento já não passavam só, nem sobretudo, pelo mercado interno metropolitano: a política de substituição de importações dava lugar a procedimentos que conferiam a primazia à exportação.

Por outras palavras, assistiu-se no início da década de 60 a uma redobrada atenção pelos mercados externos, ainda eventualmente contraditória e não muito entusiástica, onde se manifestaram duas grandes tendências: uma primeira que significa avançar para as colónias (construção do "espaço único português"/"mercado comum português"), outra, conduzindo a um aprofundamento nos movimentos de integração europeia, na circunstância através da adesão à EFTA (consagrando um fenómeno irreprimível uma vez que a Europa já era então o primeiro parceiro comercial de Portugal).

Mesmo arriscando algum simplismo, a análise pode ser transporta para a quase obrigatoriedade com que Portugal faz o seu pedido de adesão ao GATT em Maio de 1960. Propósito que, de resto, precipitaria a institucionalização do já referido Espaço Económico Português, anunciado publicamente em Junho de 1961 e criado por lei em Novembro do mesmo ano. A forma como 
o projeto foi publicamente apresentado fê-lo surgir como um refúgio para a redenção do Império, única alternativa para o pôr a salvo das forças, que interna e externamente, pugnavam pelo seu desmembramento. Entretanto, em Março de 1961, começara a guerra colonial em Angola.

Quanto ao GATT, Portugal não tinha sido sequer convidado pelos EUA para tomar parte na conferência que reuniu em Genebra os 23 países mais importantes no quadro do comércio mundial para negociar reduções de direitos aduaneiros e que conduziu à assinatura, a 30 de Outubro de 1947, do Acordo Geral sobre Pautas Aduaneiras e o Comércio / GATT, só vindo a assinar esse acordo em 6 de Abril de 1962.

\section{UM PÉ EM ÁFRICA MAS OS OLHOS NAS COMUNIDADES: A COOPERAÇÃO POSSÍVEL}

Tudo parecia caminhar de feição para as autoridades portuguesas quando, em 9 de Agosto de 1961, a Grã-Bretanha, com a companhia dos países escandinavos, reclamou a sua integração no Mercado Comum. Neste ponto, Salazar hesitou... Os riscos cuidadosamente medidos eram de monta: no horizonte surgia mais uma vez o espectro do isolamento no contexto europeu. Relutantemente, mas dando provas da flexibilidade necessária, o Presidente do Conselho, em 18 de Maio de 1962, solicitou por carta entregue pelo Embaixador Calvet de Magalhães ao Presidente da CEE, "a abertura de negociações entre Portugal e a Comunidade com o fim de definir os termos da colaboração que o Governo português queria ver estabelecida com os países do Mercado Comum"21.

Sem expor pretensões ou reservas Oliveira Salazar adoptava a fórmula vaga que na altura lhe permitia evitar escolhos maiores. Até porque existia a Grã-Bretanha e a Commonwhealth cujos problemas de integração na CEE haviam de forçosamente lançar pistas de soluções aplicáveis ao Ultramar português.

Providencialmente o Presidente De Gaulle, na sua célebre declaração de 13 de Janeiro de 1963 pôs uma pedra sobre o assunto, recusando liminarmente a integração do Reino Unido na Comunidade: "fazendo fracassar subitamente as negociações em curso com a Inglaterra, todos os preparativos para as negociações com os restantes membros da EFTA ficaram automaticamente prejudicados" 22 .

Todavia, anos mais tarde, o próprio Presidente do Conselho, começaria a manifestar alguns sinais de resignação face à constituição de uma unidade de estrutura económica da Europa... Referindo-se à possibilidade de a Europa poder vir a constituir uma «terceira força», independente e a par dos dois pólos de força representados pelos Estados Unidos e a União Soviética, era convicção de Oliveira Salazar que, ultrapassados alguns problemas como 
a atual divisão que, no domínio económico, não permite que a Europa seja considerada um todo, penso que ela poderá e deverá desempenhar esse papel de «terceira força», o que, aliviando os Estados Unidos das grandes responsabilidades atuais, daria à Europa maior poder e maior liberdade de ação. Se me refiro apenas à unidade de estrutura económica, é que não me parece necessário nem possível, tanto quanto podemos ver no futuro, que a Europa seja para tal efeito integrada de forma a constituir uma unidade política. Esta é a meu ver dispensável, mas já não o é que a Europa saiba forjar outro elemento da sua força potencial - a vontade de assumir aquela responsabilidade. É a falta dessa vontade que poderá constituir o principal obstáculo ${ }^{23}$.

Seja como for, o problema só voltou a pôr-se quase uma década depois. Já eram outros os atores quando em 1970 a candidatura britânica de adesão às Comunidades Europeias é finalmente aceite.

Portugal compreendeu novamente que não podia ficar à margem, partindo para as negociações que efetivamente iniciadas em Dezembro de 1971, haveriam de conduzir à assinatura do Acordo de Comércio Livre Portugal - CEE e do Acordo Portugal - CECA sobre o comércio dos produtos siderúrgicos em 22 de Julho de 1972. Decisão que, tendo a ver fundamentalmente com a avaliação dos condicionalismos de ordem comercial, se defrontou com posições contrárias protagonizadas pela ala mais conservadora do regime argumentando com os perigos do 'contágio político' e com o risco de abrandar o 'empenhamento ultramarino'.

Em boa verdade, o Governo Português, agora liderado por Marcelo Caetano, tinha um posicionamento mais positivo em relação à 'via europeia', o que levou a adoptar um empenhamento mais afirmativo na problemática europeia, no quadro de uma ligação real e institucional, mesmo modesta, à CEE. Atente-se, por exemplo, no despacho ministerial de 23 de Março de 1970: "É necessário proceder ao estudo da situação presente e das possibilidades futuras no que respeita aos processos da participação do País nos movimentos que têm por objectivo a integração económica da Europa." 24

No mesmo sentido foi criada a Comissão de Estudos sobre a Integração Económica Europeia, composta por alguns dos mais influentes diplomatas portugueses, presentes nas negociações internacionais desde os tempos da OECE, a que se juntam alguns dos mais destacados economistas portugueses da época ${ }^{25}$.

Em particular, aqueles que integraram a Comissão de Estudos sobre a Integração Económica Europeia, cuja presidência fora entregue a Rui Teixeira Guerra, defenderiam sempre, com a clarividência em relação ao futuro, que as 
negociações fossem conduzidas no sentido de excluir qualquer possibilidade que pudesse comprometer uma adesão futura, ou seja, em circunstância alguma proferir declarações ou expor ideias "que envolvam uma contradição doutrinária a respeito dos princípios que informam a $\mathrm{CEE}^{\text {"26. }}$. O relatório apresentado pela Comissão concluiu no sentido de aconselhar vivamente uma associação à Comunidade, apontando, entre outros aspectos, não se afigurar "viável um acordo com a Comunidade em que participem os territórios ultramarinos portugueses, podendo até acontecer que o simples facto se levantar desde já o problema, provoque reações suficientemente fortes para diminuir, de modo considerável, as já reduzidas possibilidades de êxito de uma negociação relativa à Metrópole"27.

De resto, o projeto do Espaço Económico Português parecia estar desde início condenado ao fracasso e não só por aquelas razões óbvias que as próprias autoridades desde sempre reconheceram e infrutiferamente procuraram obviar: mais de dois terços do comércio externo português continuava a fazer-se com os países europeus; a reafectação das atividades económicas, pedra fundamental do empreendimento, nunca chegaria a operarse, não passando mesmo de uma fase incipiente; a questão dos pagamentos interterritoriais, sobretudo na segunda metade da década, tornar-se-ia um problema estrutural e transformou-se mesmo numa das mais importantes preocupações do Governo: no fundo era uma consequência dos diferentes níveis de desenvolvimento que se verificavam entre os diferentes territórios e a da própria insegurança que neles se instalou como consequência das guerras de libertação.

De certa forma a "época de ouro" do capitalismo mundial também teve a sua expressão nos anos 60 portugueses: a taxa de crescimento do PIB andou pelos $7 \%$ (média anual) e a da indústria transformadora ultrapassou os $9 \%$. Mas esta evolução, apesar de tudo positiva, processou-se num quadro de restrições que pesaram duramente no balanço a fazer. O insucesso da constituição do Mercado Único Português, a guerra colonial, o aumento dos salários alimentado pela aceleração da emigração, a lentidão com que se processavam as reformas "urgentes", o próprio enfraquecimento da EFTA (com a adesão à CEE da Inglaterra - principal parceiro comercial de Portugal - Dinamarca e Irlanda) e por fim, o "choque petrolífero de Outubro de 1973 e o consequente aumento dos preços internacionais das matérias-primas energéticas, vieram tornar ineficazes os esforços feitos e desarticular, votando ao fracasso os sucessivos modelos de política económica e industrial que foram sendo construídos.

Em 1972 e 1973 a situação deteriorou-se dramaticamente e, na prática cessaram as condições de crescimento: as contas externas apresentavamse fortemente negativas, a inflação aumentou, o mercado de capitais, artificialmente desenvolvido soçobrou na queda da Bolsa de Valores (Outubro/ 
Novembro de 1973).

No fundo, quebrada a confiança, praticamente paralisado o investimento produtivo, o sistema perdeu condições de funcionamento porque tinham sido, finalmente, postos em causa os equilíbrios que durante décadas foram sendo laboriosamente tecidos e arbitrados.

Quando as condições externas se alteraram, as fragilidades internas, vieram com estrépito ao de cima. Assim, se num primeiro momento, a crise internacional, o choque petrolífero, e depois o 25 de Abril, determinaram a interrupção da dinâmica em curso, foi também a Revolução que 'disfarçou' o lado mais dramático que a situação de ruptura económica e financeira, acabando por abrir a via para o aparecimento de alternativas que o marcelismo esgotado já não tinha capacidade para empreender.

\section{RUMO À EUROPA: DA COOPERAÇÃO PROCURADA À INTEGRAÇÃO COMO FUTURO}

A Revolução de 25 de Abril de 1974 veio, por fim, derrubar o último governo do Estado Novo. De imediato, iniciaram-se as negociações com os movimentos de independência das colónias portuguesas em terras de África. O processo revolucionário, a recomposição de um País que saía de 40 anos de regime ditatorial, abriu as portas a meses de intensa instabilidade: os governos provisórios sucederam-se, as diversas facções definiram-se, lutando pelo poder e confrontando-se; a descolonização foi cumprida, lutou-se pela democratização do País e pela defesa das liberdades fundamentais, impondose a elaboração de uma nova Constituição para a República.

A vitória coube à democracia e ao pluralismo partidário: em 25 de Abril de 1975 realizaram-se as primeiras eleições livres dos últimos 50 anos, para uma Assembleia Constituinte; a 2 de Abril de 1976 foi aprovada a nova Constituição e a 25 de Abril de 1976 realizaram-se as primeiras eleições legislativas para a Assembleia da República, em Junho as eleições para a Presidência da República e em Julho seguinte, o I Governo Constitucional tomou posse.

Com a situação política enquadrada constitucionalmente e as movimentações sociais em período de relativa acalmia, as principais preocupações do Governo centraram-se então, prioritariamente, na normalização democrática, no reforço da reconciliação nacional e na resolução dos graves problemas económicos deixados em aberto pela Revolução: os efeitos da descolonização, a perda dos mercados tradicionais, a desorganização do sistema produtivo e financeiro e o tradicional deficit comercial com o exterior, tudo isto agravado por uma crise mundial de que os portugueses, empenhados na resolução dos seus próprios problemas, mal se apercebiam.

Em matéria de relações externas, tal como nos outros campos, mas 
aqui porventura com maior intensidade, a Revolução significou uma ruptura profunda e sem retorno. No que respeita à posição de Portugal em matéria de cooperação europeia desenhou-se um novo ciclo, que compreendeu dois tempos específicos entre o 25 de Abril e o pedido formal de adesão à CEE em 1977.

Um primeiro período, seguiu-se imediatamente aos acontecimentos de Abril de 1974, dominado pela descolonização, por diplomacias paralelas, por indefinições várias e pela demonstração de um fascínio, exibido por parte de algumas forças civis e militares, por uma espécie de terceiromundismo. O outro período, já em plena vigência da Constituição, iniciado com a posse do I Governo Constitucional, é não só marcado pelo regresso à normalidade democrática mas pela redescoberta da vocação europeia e atlantista e o recentramento do País no contexto europeu. Portugal, já sem o Império, procurava uma nova identidade e um novo desígnio nas relações internacionais. Complementarmente, assumia-se como uma nação pacífica atribuindo grande importância ao bom relacionamento e ao reforço dos laços de amizade com as suas antigas colónias. Para todos os efeitos, estava definitivamente ultrapassada a época do isolacionismo, refúgio e reflexo de impotências várias, e tudo podia, de novo, ser posto em causa: era necessário reencontrar um rumo e definir estratégias e percursos, avaliar possibilidades, trilhar caminhos novos e reajustar outros antigos.

Tornou-se então evidente e denodado o esforço no sentido da descoberta de um caminho que permitisse reencontrar a posição de Portugal na Europa, à época também ela mergulhada na busca de uma nova identidade, e no Mundo onde a globalização passaria a marcar o ritmo de transformações aceleradas.

A evolução da história de Portugal, o seu reconhecimento num quadro democrático, os reacertos e reajustamentos na procura de um novo posicionamento internacional ditado quer pelas conjunturas e estratégias nacionais, quer pelas próprias dinâmicas internacionais, conheceu então mutações profundas, de natureza e de ritmo.

Para os novos responsáveis políticos era naturalmente fundamental reanimar e modernizar a economia portuguesa, dotando-a de estruturas e imprimindolhe um dinamismo que permitissem a sua evolução no sentido do modelo adoptado pelas economias das democracias ocidentais.

A aproximação de Portugal às estruturas europeias teve início logo em 1976, com a integração no Conselho da Europa e a renegociação do Acordo de Comércio Livre Portugal-CEE de 1972 que culminou com a assinatura de alguns protocolos adicionais. A integração de Portugal nas Comunidades Europeias colocou-se então como uma meta fixada pelo Governo. Sucederamse vários contactos e o Presidente do Conselho de Ministros da CEE visitou Portugal; em Agosto de 1976 o primeiro-ministro, Mário Soares, apresentou 
na Assembleia da República o programa do I Governo Constitucional, que incluía a defesa da integração de Portugal na Comunidade Económica Europeia; por fim, em 29 de Novembro de 1976, o Governo português foi autorizado a solicitar a adesão de Portugal às Comunidades Europeias. Nos primeiros meses de 1977 as autoridades portuguesas desencadearam uma importante ação diplomática no sentido de conjugar apoio para a adesão portuguesa junto dos chefes de Estado e de Governo dos países comunitários. Por fim, Portugal solicitou formalmente a sua adesão às Comunidades Europeias.

O pedido de adesão à então denominada Comunidade Europeia, formalmente apresentado por carta dirigida pelo primeiro-ministro, Mário Soares, ao Presidente do Conselho das Comunidades Europeias em 28 de Março de 1977, ficou a representar um enorme ponto de viragem nas relações internacionais e, em particular, na política externa portuguesa. Os argumentos utilizados, bem conhecidos, serviram quer para justificar a adesão, quer para acabar com algumas veleidades de "independência nacional", fundamentadas num desenvolvimento autocentrado, defensivo e protecionista, que era preconizado por algumas organizações políticas e sociais: primeiro porque a integração na Europa representava não só o reconhecimento definitivo de Portugal como um estado democrático e de direito como constituía um poderoso reforço da nossa, como então se dizia, frágil democracia; depois, segundo argumento, porque o regresso às fronteiras europeias determinava um novo esforço de modernização e de desenvolvimento que só a solidariedade dos países mais ricos da Europa, traduzida em ajudas comunitárias, poderia propiciar.

\section{NOTA FINAL}

A história da participação de Portugal no processo de construção europeia, respeitando o compasso dialogante entre a conjuntura internacional e o processo de cooperação/integração entre os países europeus, fez-se a dois ritmos, o da inevitabilidade europeia e o da inexorabilidade colonial, evoluiu em três tempos, entre o salazarismo e o marcelismo, e cumpriu-se a seguir à Revolução que instaurou a Democracia.

O envolvimento, e mesmo a participação ativa, nas dinâmicas de cooperação e integração europeia desencadeadas a partir do final do conflito mundial figuraram entre as consequências mais significativas dos efeitos da II Guerra e do pós-Guerra em Portugal, inscrevendo-se também, por íntima associação, na apreciação do período de crescimento e modernização que caracterizou a economia portuguesa na segunda metade do século XX. É que, na verdade, foi também por arrastamento dos efeitos da Guerra, sobretudo na sequência dos acontecimentos que compuseram a participação do País no Plano Marshall, que Portugal se viu envolvido num processo de crescente abertura ao exterior e de internacionalização da economia nacional: através 
do seu envolvimento no Plano Marshall, da sua adesão à OECE, à União Europeia de Pagamentos (UEP), Portugal garantiu a sua integração no sistema de comércio e de pagamentos construídos no pós-guerra e a sua presença ativa nos movimentos nascentes de cooperação económica europeia.

Essa aproximação, desde o fim da Guerra até ao final do salazarismo, operou-se todavia num quadro de quase inevitabilidade, sobretudo por pressão da realidade internacional. Sempre que necessário, predominou o pragmatismo e o sentido de oportunidade: o Governo português compreendeu desde sempre que 'não podia ficar de fora', e esse foi o desígnio determinante que acabou por imperar e conduzir ao envolvimento do País nos principais momentos de cooperação internacional a que lhe foi dado acesso, acabando por lhe proporcionar a sua aceitação e integração no sistema internacional emergente nos anos do pós-Guerra. Não se tratou de uma opção solitariamente assumida mas sim de uma inexorabilidade e de uma reacção, prova do peso do 'cerco' internacional', que se procurou combinar com a viragem para as colónias. No fundo, tentou-se preservar o essencial da realidade existente, procurando, tanto quanto possível, conciliar duas trajectórias tendencialmente divergentes: autarcia e internacionalização.

Já com Marcelo Caetano no poder, a partir de 1968, e no quadro do que ele mesmo designou por "renovação na continuidade", os novos termos em que se colocava o prosseguimento da modernização da economia e indústria portuguesas, foram efetivamente (ainda que transitoriamente e sem grande êxito) alterados. As expectativas eram ambiciosas, apostando num vasto conjunto de reformas, que nomeadamente em matéria económica, conduziriam à modernização do País, à melhoria do nível de vida da população e ao desenvolvimento económico duradouro.

As principais 'novidades económicas' do marcelismo, pesando os legados herdados, refletir-se-iam, muito sumariamente, no domínio da política económica, acentuando a aposta nas práticas de planeamento, na tentativa de esbater o protecionismo interno e externo e na abertura ao exterior. Apostouse na renovação da estratégia industrial, sobressaindo nesse âmbito duas novidades importantes, a criação do Pólo de Sines e a promulgação da Lei do Fomento Industrial. Procurou-se ainda estimular o investimento estrangeiro, combinando-o com a aposta na aproximação à Europa, que se traduziu num envolvimento mais empenhado em matéria de cooperação económica, que facilitou a celebração do acordo de comércio livre com a CEE em 1972.

Numa primeira fase, a cooperação europeia impôs-se pela inexorabilidade da dependência externa, especialmente económica, de Portugal. Foi conduzida sob inequívoca subordinação aos objectivos políticos do Estado Novo, não obstante e por via do paradoxo que imperava na política económica nacional almejando a autarcia económica sem todavia promover a modernização do tecido produtivo português. Embora os princípios e os 
primados que conduziam e orientavam a política externa portuguesa, bem como as preferências que se colocavam na eleição dos seus parceiros à condição de privilégio, escapassem aos pressupostos da cooperação entre os países europeus e aos desígnios do comando internacional sob a ordem da Guerra Fria, a afirmação de Portugal no contexto internacional acabaria, precisamente, por integrar e até combinar a aproximação tantos aos EUA como aos países europeus em modo de cooperação. Nesse contexto, ganharia evidente protagonismo a diplomacia europeia, especialmente económica, que, a prazo, se afirmaria essencial no percurso português. Foi esta que, paradoxalmente, se afirmou tanto no contexto de abertura e modernização que caracterizou o País até à crise do início dos anos 70 como, ainda sob o Estado Novo, abriu caminho a novas fórmulas de cooperação europeia e, a breve trecho, já em contexto de democracia conduziu à integração europeia.

\section{NOTAS}

${ }^{1}$ Regime ditatorial que vigorou em Portugal entre 1933 e 1974, chefiado sucessivamente por Oliveira Salazar e Marcelo Caetano.

${ }^{2}$ GERBET, Pierre. La Construction de l'Europe, Paris: Imprimerie Nationale, 1983, p.55.

${ }^{3}$ ROLLO, Maria Fernanda. Portugal e a II Guerra: limites políticos e legados económicos. In: CAPUZZO, Paola e GIORGI, Chiara (orgs.), Centro e Periferia come Categorie Storiografiche. Esperienze do ricerca in Italia, Spagna e Portagallo. Roma: Quaderni del Dipartamento di Discipline Storiche Universitá di Bologna, Carocci de Roma, 2009, pp.71107.

${ }^{4}$ Lei no 2002, da Electrificação do País, Diário do Governo, I Série, 26 de Dezembro de 1944 e Lei no 2005, Diário do Governo, I Série, nº 54, 14 de Março de 1945.

${ }^{5}$ ROLLO, Maria Fernanda. Heranças da Guerra: o reforço da autarcia e os 'novos rumos' da política económica. Ler História, nº 50, 2006, pp. 115-153.

${ }^{6}$ LOPES, José da Silva. A economia portuguesa no século XX. In: PERES, Fernando (Coord.), Panorama da Cultura Portuguesa no Século XX, 1. As Ciências e as Problemáticas Sociais, Porto: Edições Afrontamento, 2001 / Fundação Serralves, 2002, p. 311.

${ }^{7}$ ROLLO, Maria Fernanda. Portugal e o Plano Marshall. Lisboa: Editorial Estampa, 1994.

${ }^{8}$ ROLLO, Maria Fernanda. 'Senhor Europa'. Homenagem a Rui Teixeira Guerra”. Ingenium, Revista da Ordem dos Engenheiros, II Série, n 111, Maio/Junho 2009, p. 89-91.

${ }^{9}$ ROLLO, Maria Fernanda. Portugal e a Reconstrução Económica do Pós-Guerra. O Plano Marshall e a Economia Portuguesa dos anos 50. Lisboa: Ministério dos Negócios Estrangeiros, 2007.

${ }^{10}$ Diário do Governo no 204, I Série, de 1 de Setembro de 1948.

${ }^{11}$ ROLLO, Maria Fernanda. Salazar e a Construção Europeia. Penélope, $\mathrm{n}^{\circ} 18$, Edições Cosmos, 1998, pp. 51-76.

${ }^{12}$ CAETANO, Marcelo. Discurso inaugural dos Congressos dos Economistas Portugueses e da Indústria Portuguesa. In: AAVV. Discursos, Conclusões e Estudos Sobre a Indústria Portuguesa, II Congresso da Indústria Portuguesa. Lisboa: Associação Industrial Portuguesa, 
Lisboa, 1957, p. 15.

${ }^{13}$ Cf. Conclusões Gerais. In: AAVV, Discursos, Conclusões e Estudos Sobre a Indústria Portuguesa, II Congresso da Indústria Portuguesa, Lisboa: Associação Industrial Portuguesa, 1957, pp. 17 a 25.

${ }^{14}$ GUERRA, Rui Teixeira, MAGALHÃES, Calvet de e FREIRE, Siqueira. Os Movimentos de Cooperação e Integração Europeia no Pós-Guerra e a Participação de Portugal nesses Movimentos. Lisboa: INA, Departamento de Integração Europeia, 1981, p.8.

${ }^{15}$ ROLLO, Maria Fernanda. José Calvet de Magalhães e a Construção Europeia. Relações Internacionais, $\mathrm{n}^{\circ}$ 8, Dezembro de 2005, pp. 121-129.

${ }^{16}$ Idem, p. 50.

${ }^{17}$ LOPES, José da Silva. Associação Europeia de Comércio Livre (AECL)/EFTA. In: Dicionário de História do Estado Novo. Lisboa: Círculo de Leitores, p. 73-74.

${ }^{18}$ Cf. XAVIER, Alberto Pinheiro. Portugal e a Integração Europeia. Coimbra: Livraria Almedina, 1970, pp. 116 a 121.

${ }^{19}$ Cf. PINTO, L. M. Teixeira, Portugal e a integração económica europeia. In: II Congresso da Indústria Portuguesa, Comunicação ${ }^{\circ}$ 122, Lisboa: Associação Industrial Portuguesa, 1957, p. 35.

${ }^{20}$ SALAZAR, António de Oliveira. Discursos e Notas Políticas, vol. V. 1951-1958, Coimbra: Coimbra Editora, 1959, p. 439.

${ }^{21}$ SALAZAR, António de Oliveira. Entrevistas, 1960-1966. Coimbra: Coimbra Editora, 1967, p. 148.

${ }^{22}$ GUERRA, op.cit., p. 52.

${ }^{23}$ SALAZAR, António de Oliveira. Entrevistas, 1960-1966. Coimbra: Coimbra Editora, 1967, p. 220

${ }^{24}$ Diário do Governo, no 69, II Série, de 23 de Março de 1970.

${ }^{25}$ A Comissão era composta por Rui Teixeira Guerra, José Calvet de Magalhães, Alberto Nascimento Regueira, Álvaro Ramos Pereira, Carlos Lourenço, Ernesto Fervença da Silva, Eugénio Castro Caldas, Ilídio Barbosa, João Cravinho, José da Silva Lopes, Luís Figueira, Rui dos Santos Martins e João Vieira de Castro.

${ }^{26}$ GUERRA et alia. op.cit., p. 22.

${ }^{27}$ Relatório da Comissão de Estudos sobre a Integração Económica Europeia, policopiado, Setembro de 1970, p. 137.

Artigo recebido em janeiro de 2015. Aceito em julho de 2015. 